\begin{tabular}{|c|c|c|}
\hline$A B$ & $\begin{array}{l}\text { European Association for the } \\
\text { Development of Renewable Energies, Environment } \\
\text { and Power Quality (EA4EPQ) }\end{array}$ & $\begin{array}{l}\text { International Conference on Renewable Energies and Power Quality } \\
\text { (ICREPQ'12) } \\
\text { Santiago de Compostela (Spain), 28th to 30th March, } 2012\end{array}$ \\
\hline
\end{tabular}

\title{
A novel tool for voltage event characterization based on the Wavelet theory
}

\author{
J. Bruna $^{1}$, J.J. Melero ${ }^{1}$, J. Díaz de Aguilar $^{2}$, M.L. Romero ${ }^{2}$ \\ ${ }^{1}$ CIRCE - University of Zaragoza, Zaragoza, Spain \\ C/ Mariano Esquillor Gómez, 15 - Zaragoza 50018 (Spain) \\ Phone/Fax number: +0034976 762402,e-mail: jbruna@unizar.es/melero@unizar.es \\ ${ }^{2}$ CEM (Centro Español de Metrología), Madrid, Spain \\ $\mathrm{C} /$ del Alfar, 2 - Tres Cantos, Madrid (Spain) \\ Phone/Fax number:+0034918074 715,e-mail: jdiaz@,cem.mityc.es/mlromero@,cem.mityc.es
}

\begin{abstract}
The actual methods for analyzing the starting point of any event are unable to define correctly this kind of phenomena with enough accuracy. Methods based on RMS calculation often have substantial errors in time and highly depend on the phase of the voltage waveform. In spite of this previous disadvantage, these methods are being used in most of the PQ analyzers.

This paper develops a novel method to characterize accurately the parameters that define each event (dips, swells and interruptions), mainly the duration, start and end instant by the calculation of the root mean square value during the disturbance. The wavelet theory will be used in the development of the method.
\end{abstract}

\section{Key words}

Voltage event, dips, swells, interruptions, digital filter

\section{Introduction}

According to EN 50160 standard [1], supply voltage events are characterized by two parameters: magnitude and duration. Regarding with magnitude, two voltage levels must be calculated:

- The depth of the voltage dip/interruption, defined as the difference between the reference voltage and the residual voltage often expressed as a value in volts or as a percentage or per unit value of the reference value. For swells, this difference is calculated from the maximum swell magnitude voltage and the reference voltage.

- The reference voltage, the value specified as the base on which the differences are expressed in per unit.

These magnitudes are normally measured using the following methods:

1. Root Mean Square calculation

2. Peak Value evaluation

Most measurement devices include the root mean square calculation algorithm for its simplicity and low calculation requirements. For these reasons, this method is proposed in power quality standards.

Time characterization is another important issue to be tracked during the event phenomena characterization. The duration is mainly determined by the operating time of protection relays or other devices used to clear the faults in the power system [2]. This parameter is obtained from the start and end values of the detection algorithm.

Paradoxically, the most adopted method (root mean square calculation) lacks of the necessary time sensitivity due to its dependency with the length of the measurement window. Besides, it does not provide accurate results of event start/end instants to quantify this kind of disturbance.

The application of the wavelet transform to power quality phenomena has recently experienced an important development $[3,4,5]$. For these reasons, the use of wavelet theory has allowed developing a more sensitive algorithm to sudden changes in amplitude. In this paper, a novel method, where duration and amplitude are obtained accurately, is proposed. Additionally, a Matlabbased interface has been developed to verify the correct design and operation of the algorithm.

\section{Principles of measurement}

Two different methods of characterizing voltage events are explained below.

\section{Discrete RMS method}

This method is based on the root mean square mathematical definition of a continuous waveform defined over the interval $t_{1} \leq t \leq t_{2}$ :

$$
f(t)_{r m s}=\sqrt{\frac{1}{t_{2}-t_{1}} \int_{t_{1}}^{t_{2}}(f(t))^{2} d t}
$$

For $n$ samples, its discrete form corresponds to:

$$
r m s=\sqrt{\frac{1}{n} \sum_{i=1}^{n} x_{i}^{2}}
$$


This method is usually defined for periodic waveforms, although it can also be used for non-periodic signals. The result of this procedure tightly depends on the length of the measurement window. The size can vary between $1 / 2$ cycle $(10 \mathrm{~ms}$ for a power frequency of $50 \mathrm{~Hz}$ ) to any multiple of $1 / 2$ cycle. According to the IEC 61000-4-30 [6], the value of the rms must be measured over 1 cycle, commencing at a fundamental zero crossing and refreshed each half-cycle.

With these considerations, the ideal rms (dotted green line) and the calculated $U_{\text {rms(1/2) }}$ (red line) are represented in Figure 1 for a voltage dip of $40 \%$-magnitude and $40 \mathrm{~ms}-$ duration. The sampling rate was set to $36 \mathrm{kS} / \mathrm{s}$.

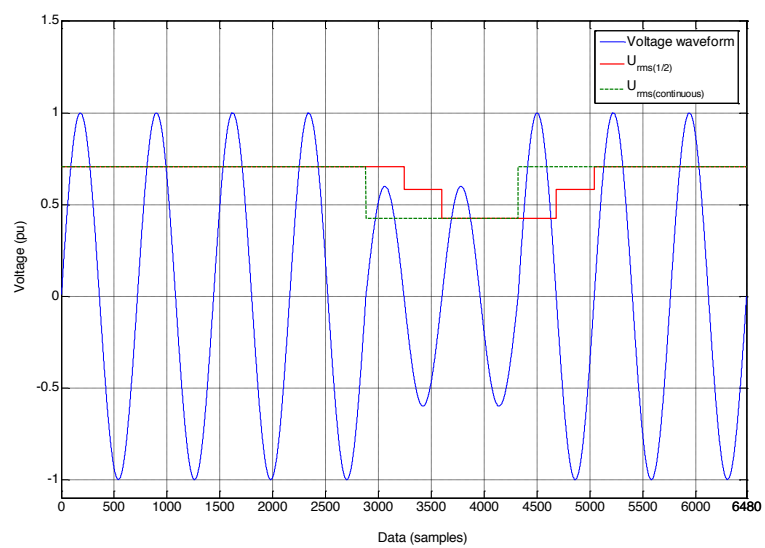

Figure 1. RMS detection comparative.

The results, shown in Figure 1, allow concluding that the $U_{\text {rms( } 1 / 2)}$ method has an important delay due to the definition of the measurement window and its refreshing rate. According to the power quality standard, IEC 610004-30 [6], a new rms value is calculated every new $1 / 2$ cycle (10 ms), giving important errors when short-duration events are evaluated.

To illustrate this issue, a new waveform was generated with a residual voltage of $60 \%$ and a duration of $16,08 \mathrm{~ms}$ as shown in Figure 2. The $U_{\operatorname{rms}(1 / 2)}$ method is unable to accurately detect both, time and amplitude at the same time (note that the voltage dip does not remain a complete cycle).

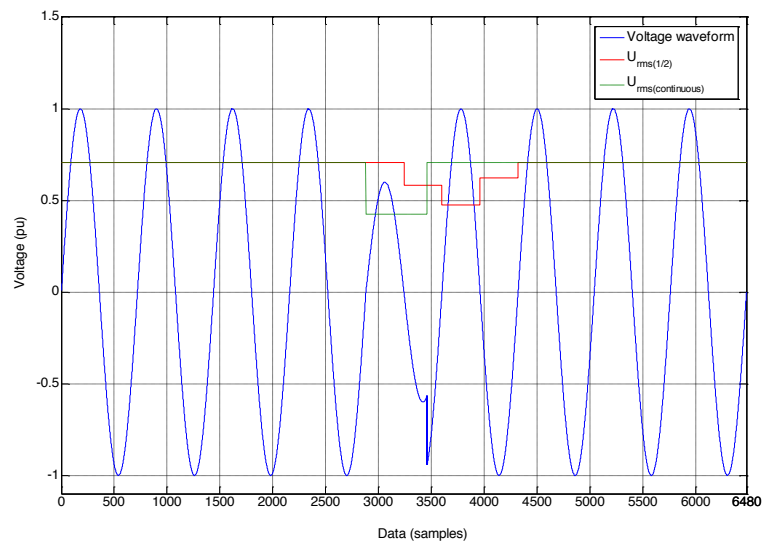

Figure 2. RMS detection comparative. Short-duration events

Additional tests, varying the event magnitude and duration, revealed excessive errors in the rms calculation (up to $65 \%$ from theoretical rms value) and duration evaluation (up to $50 \%$ ).

It is clear that the $U_{\text {rms(1/2) }}$ method cannot be used to properly track sudden changes in voltage levels, giving inaccurate results when short-duration events must be analysed.

\section{Wavelet transform method}

The method is first based on the continuous wavelet transform. A wavelet $\psi$ is a function of zero average:

$$
\int_{-\infty}^{+\infty} \psi(t) d t=0
$$

which is stretched with a scale parameter $s$, and translated over the time by $u$, according to:

$$
\psi_{u, s}(t)=\frac{1}{\sqrt{s}} \psi\left(\frac{t-u}{s}\right)
$$

Substituting Eq.4 into Eq.3:

$$
W f(u, s)=\int_{-\infty}^{+\infty} f(t) \frac{1}{\sqrt{s}} \psi^{*}\left(\frac{t-u}{s}\right) d t
$$

Wavelet transform is used for time-frequency measurements, always according to the Heisenberg uncertainty principle [7]. When $s$ varies, time and frequency spread are respectively proportional to $s$ and $1 / s$, but maintaining its area constant.

While wider mathematical background of Wavelet Transform can be found in $[8,9,10]$, the wavelet decomposition function is easily constructed using specific digital filters (discrete wavelet transform) for this particular implementation. The signal passes through a half band digital filter with impulse response (FIR or IIR). Filtering the signal is equal to apply the convolution operation to the input sequence with the response of the filter:

$$
x[n] * h[n]=\sum_{k=-\infty}^{\infty} x[k] \cdot h[n-k]
$$

This method is very sensitive to slight changes in frequency content due to the filter impulse response. This property makes this method perfect for tracking voltage events.

\section{Developed method - Tests}

The model of the algorithm for event detection was implemented as follows. The input signal is convoluted with one specific digital filter. The chosen filter is an IIR Butterworth filter with 29 coefficients. The frequency rate of the system is $12.8 \mathrm{kS} / \mathrm{s}$ being the maximum time resolution:

$$
\delta=\frac{1}{12.8 k S / s}=78.125 \mu s
$$

The validity of the method was proofed varying the amplitude of the input wave from $0.95 \mathrm{pu}$ to $0.05 \mathrm{pu}$. All the tests start at $100 \mathrm{~ms}($ data $=1281)$ and end at $120 \mathrm{~ms}$ $($ data $=1537)$ as shown in Figure 3. 


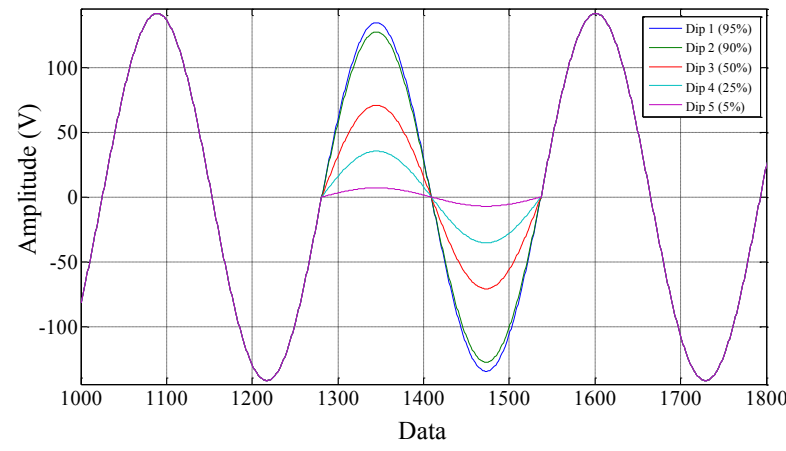

Figure 3. Event depth variations

The results obtained for the five previous tests show a constant detection delay regardless of the voltage variation as can be seen in Table 1 .

Table 1. Event depth variation results

\begin{tabular}{c|cccc}
\hline $\begin{array}{c}\text { Event } \\
\text { RMS }\end{array}$ & $\begin{array}{c}\text { Event } \\
\text { start } \\
\text { (sample) }\end{array}$ & $\begin{array}{c}\text { Event start } \\
\text { detection } \\
\text { (sample) }\end{array}$ & $\begin{array}{c}\text { Event end } \\
\text { (sample) }\end{array}$ & $\begin{array}{c}\text { Event end } \\
\text { detection } \\
\text { (sample) }\end{array}$ \\
\hline $\mathbf{9 5 , 0} \%$ & $\mathbf{1 2 8 1}$ & 1291 & $\mathbf{1 5 3 7}$ & 1547 \\
$\mathbf{9 0 , 0} \%$ & $\mathbf{1 2 8 1}$ & 1291 & $\mathbf{1 5 3 7}$ & 1547 \\
$\mathbf{5 0 , 0} \%$ & $\mathbf{1 2 8 1}$ & 1291 & $\mathbf{1 5 3 7}$ & 1547 \\
$\mathbf{2 5 , 0} \%$ & $\mathbf{1 2 8 1}$ & 1291 & $\mathbf{1 5 3 7}$ & 1547 \\
$\mathbf{5 , 0} \%$ & $\mathbf{1 2 8 1}$ & 1291 & $\mathbf{1 5 3 7}$ & 1547 \\
\hline
\end{tabular}

The influence of the relative start instant on the event detection time was also tested. Three different tests were carried out for event durations of $27.5 \mathrm{~ms}, 25 \mathrm{~ms}$ and $22.5 \mathrm{~ms}$ respectively, see Figure 4, finishing at the sample 1537 (time $=120 \mathrm{~ms})$.

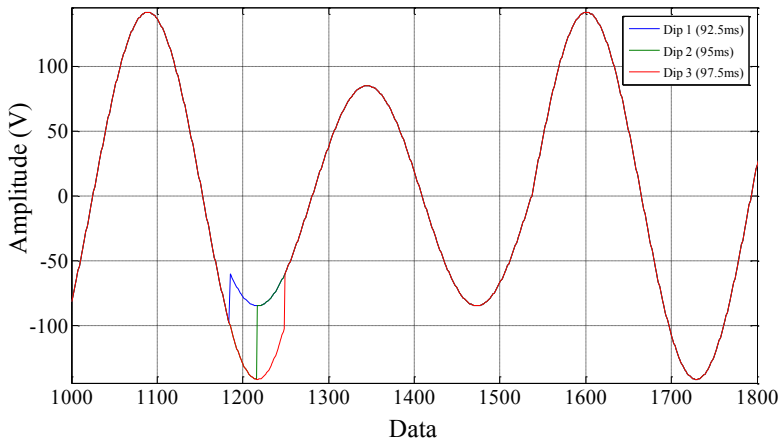

Figure 4. Event start variations

The analysis results showed the same delay for the three tested durations, 10 samples, as shown in Table 2.

Table 2. Event start variation results

\begin{tabular}{c|cccc}
\hline $\begin{array}{c}\text { Event } \\
\text { duration }\end{array}$ & $\begin{array}{c}\text { Event } \\
\text { start } \\
\text { (sample) }\end{array}$ & $\begin{array}{c}\text { Event start } \\
\text { detection } \\
\text { (sample) }\end{array}$ & $\begin{array}{c}\text { Event end } \\
\text { (sample) }\end{array}$ & $\begin{array}{c}\text { Event end } \\
\text { detection } \\
\text { (sample) }\end{array}$ \\
\hline $\mathbf{9 2 , 5} \mathbf{~ m s}$ & $\mathbf{1 1 8 5}$ & 1195 & $\mathbf{1 5 3 7}$ & 1547 \\
$\mathbf{9 5} \mathbf{~ m s}$ & $\mathbf{1 2 1 7}$ & 1227 & $\mathbf{1 5 3 7}$ & 1547 \\
$\mathbf{9 7 , 5} \mathbf{~ m s}$ & $\mathbf{1 2 4 9}$ & 1259 & $\mathbf{1 5 3 7}$ & 1547 \\
\hline
\end{tabular}

The influence of phase jumps at the starting point of the event was also checked. Seven tests were performed with phase jumps varying from $\pi / 4$ to $7 \pi / 4$ for an event with a $60 \%$ of the reference voltage as shown in Figure 5.

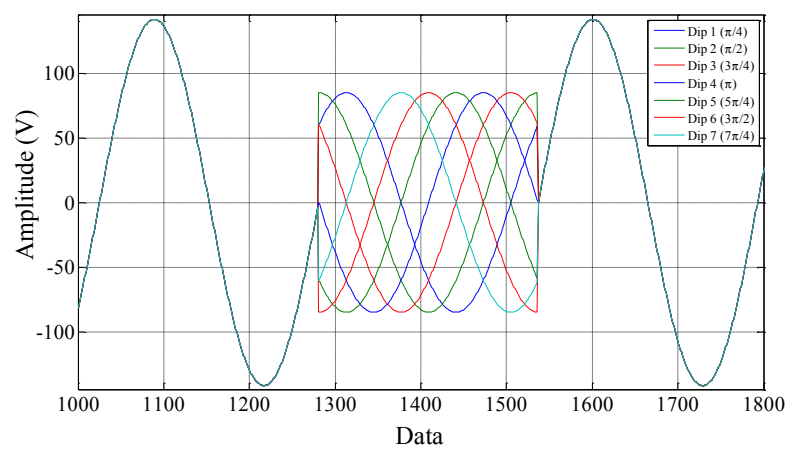

Figure 5. Phase jump variations

The results obtained are listed in Table 3.

Table 3. Phase jump variation results

\begin{tabular}{c|cccc}
\hline $\begin{array}{c}\text { Event } \\
\text { phase at } \\
\text { start }\end{array}$ & $\begin{array}{c}\text { Event } \\
\text { start } \\
\text { (sample) }\end{array}$ & $\begin{array}{c}\text { Event start } \\
\text { detection } \\
\text { (sample) }\end{array}$ & $\begin{array}{c}\text { Event end } \\
\text { (sample) }\end{array}$ & $\begin{array}{c}\text { Event end } \\
\text { detection } \\
\text { (sample) }\end{array}$ \\
\hline $\boldsymbol{\pi / 4}$ & $\mathbf{1 2 8 1}$ & 1291 & $\mathbf{1 5 3 7}$ & 1547 \\
$\boldsymbol{\pi} / \mathbf{2}$ & $\mathbf{1 2 8 1}$ & 1291 & $\mathbf{1 5 3 7}$ & 1547 \\
$\mathbf{3} \boldsymbol{\pi} / \mathbf{4}$ & $\mathbf{1 2 8 1}$ & 1291 & $\mathbf{1 5 3 7}$ & 1547 \\
$\boldsymbol{\pi}$ & $\mathbf{1 2 8 1}$ & 1291 & $\mathbf{1 5 3 7}$ & 1547 \\
$\mathbf{5} \boldsymbol{\pi} / \mathbf{4}$ & $\mathbf{1 2 8 1}$ & 1291 & $\mathbf{1 5 3 7}$ & 1547 \\
$\mathbf{3} \boldsymbol{\pi} / \mathbf{2}$ & $\mathbf{1 2 8 1}$ & 1291 & $\mathbf{1 5 3 7}$ & 1547 \\
$\mathbf{7} \boldsymbol{\pi} / \mathbf{4}$ & $\mathbf{1 2 8 1}$ & 1291 & $\mathbf{1 5 3 7}$ & 1547 \\
\hline
\end{tabular}

In contrast with simulated waveforms, real voltage signals have additional noise content. Wavelet coefficients are very sensitive to small changes so it is necessary to determine automatic trigger levels to avoid false detections. Therefore, the algorithm calculates the sliding threshold depending on the mean $(\mu)$ and the standard deviation $(\sigma)$ of the samples around each local maximum ( \pm 10 samples $)$ :

$$
\text { Threshold }=\mu+3 \sigma
$$

The algorithm automatically detects the voltage event when the filter output exceeds the calculated threshold. The rms is therefore calculated using (Eq.2).

With these premises, the three previous different test cases were the base to perform a precise adjustment of the method in terms of detection accuracy. The 10sample offset due to the digital filter delay was corrected, giving exact time localization, within the used time resolution, for all the cases.

\section{Virtual software implementation}

Matlab environment was selected to implement the detection algorithm. A user interface was developed with the GUI builder of Matlab to verify the design easier. To facilitate the realization of the work, the algorithm was 
previously checked with pure sinusoidal waveforms. Later, some additional frequency content was added. This interface allows the user to introduce one main component (voltage event) plus two different waveforms (additional harmonic content) to simulate real voltage disturbances. The interface shows the results for the following parameters: theoretical start (ms), measured start (ms), theoretical end (ms), measured end (ms), theoretical duration (ms), measured duration $(\mathrm{ms})$, difference $(\mu \mathrm{s})$, theoretical RMS (\%), measured RMS (\%), difference (\%).

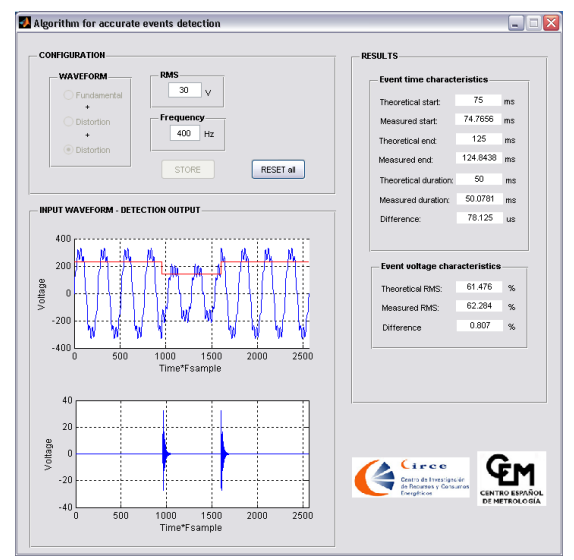

Figure 6. Event user interface

The composed waveform and its theoretical rms profile are depicted in the higher subplot while the output of the filter is represented underneath as shown in Figure 6 . The voltage event is always centered within the time axis ( $\mathrm{x}$-axis) for the desired duration.

\section{Test results}

To validate the feasibility of the proposed algorithm and the user interface, some different scenarios were evaluated. In Table 4, 10 test results were compiled for the verification of the implementation through the characterization of dips, swells and interruptions. The errors between the theoretical rms and that from the algorithm were calculated as follows:

$$
\varepsilon_{r m s}(\%)=\frac{r m s_{\text {theoretical }}-r m s_{\text {measured }}}{r m s_{\text {theoretical }}} \cdot 100
$$

$\Delta \mathrm{t}$ was also calculated according to (Eq.10):

$$
\Delta t(\mu s)=t_{\text {theoretical }}(\mu s)-t_{\text {measured }}(\mu s)
$$

being $t$ the duration of the event.

Four different rms values for the fundamental waveform were considered $(240 \mathrm{~V}, 230 \mathrm{~V}, 120 \mathrm{~V}$ and $110 \mathrm{~V})$ at $50 \mathrm{~Hz}$ and $60 \mathrm{~Hz}$. Additional frequency content was added to the fundamental wave to simulate real waveforms. These harmonic and interharmonic contents were varied from low frequencies $(150 \mathrm{~Hz})$ to higher orders $(2500 \mathrm{~Hz})$. The results showed that the accuracy of the proposed method is good enough for all the cases if they are compared with the $\mathrm{U}_{\mathrm{rms}(1 / 2)}$ method.

\begin{tabular}{|c|c|c|c|c|c|c|c|c|c|c|c|}
\hline & \multicolumn{8}{|c|}{$\begin{array}{c}\text { INPUT } \\
\text { PARAMETERS }\end{array}$} & \multirow{2}{*}{\multicolumn{3}{|c|}{$\begin{array}{c}\text { OUTPUT } \\
\text { PARAMETERS }\end{array}$}} \\
\hline & \multicolumn{4}{|c|}{ FUNDAMENTAL } & \multicolumn{2}{|c|}{$1^{\text {ST }}$ WAVEFORM } & \multicolumn{2}{|c|}{$2^{\mathrm{ND}}$ WAVEFORM } & & & \\
\hline & $\begin{array}{l}\text { Rms } \\
\text { (V) }\end{array}$ & $\begin{array}{l}\text { Frecuency } \\
(\mathrm{Hz})\end{array}$ & $\begin{array}{l}\text { Residual } \\
\text { voltage } \\
(\%)\end{array}$ & $\begin{array}{c}\text { Duration } \\
(\mathbf{m s})\end{array}$ & $\begin{array}{l}\text { Rms } \\
\text { (V) }\end{array}$ & $\begin{array}{c}\text { Frecuency } \\
(\mathrm{Hz})\end{array}$ & $\begin{array}{l}\text { Rms } \\
\text { (V) }\end{array}$ & $\begin{array}{c}\text { Frecuency } \\
(\mathbf{H z})\end{array}$ & $\begin{array}{l}\text { Theoretical } \\
\text { RMS }^{1} \text { (\%) }\end{array}$ & $\begin{array}{l}\varepsilon_{r m s} \\
(\%)\end{array}$ & $\begin{array}{c}\Delta t \\
(\mu s)\end{array}$ \\
\hline 1 & 230 & 50 & 30.0 & 40.00 & 15 & 200 & 25 & 500 & 32.310 & -0.649 & 156.250 \\
\hline 2 & 230 & 50 & 80.0 & 50.00 & 15 & 250 & 25 & 600 & 80.355 & 1.123 & 78.125 \\
\hline 3 & 240 & 60 & 50.0 & 45.00 & 15 & 180 & 25 & 300 & 51.079 & 3.754 & -78.125 \\
\hline 4 & 230 & 50 & 60.0 & 89.10 & - & - & - & - & 60.000 & 0.000 & 40.625 \\
\hline 5 & 230 & 50 & 0.0 & 60.00 & - & - & - & - & 0.000 & 0.000 & 156.250 \\
\hline 6 & 230 & 50 & 3.0 & 64.00 & - & - & - & - & 3.000 & 0.000 & 140.625 \\
\hline 7 & 120 & 60 & 30.0 & 63.01 & 50 & 150 & 20 & 250 & 49.249 & 0.965 & 36.875 \\
\hline 8 & 120 & 60 & 0.2 & 40.00 & 10 & 150 & - & - & 8.307 & -0.013 & 78.125 \\
\hline 9 & 120 & 60 & 0.1 & 45.31 & 1 & 2500 & 2 & 150 & 1.866 & -0.012 & -75.625 \\
\hline 10 & 110 & 60 & 40 & 12.00 & 5 & 250 & 10 & 1000 & 41.060 & 2.267 & -46.87 \\
\hline
\end{tabular}

Table 4.Test results

${ }^{1}$ Calculated with the combination of the Fundamental RMS during the event plus the $1^{\text {st }}$ and $2^{\text {nd }}$ waveform RMS

\section{Conclusions}

A novel method based on the Wavelet Transform was applied to characterize voltage dips, swells and interruptions. Due to the use of digital filters for analysing these kinds of phenomena, a constant delay was found and corrected. Later, a basic GUI was developed to have the configuration details and the algorithm information at a glance.
Results from the tested waveforms revealed a good behaviour of the method if compared with traditional detection implementations. The obtained overall time deviation was lower than $200 \mu$ s for all the cases while the calculated rms error does not exceed $4 \%$. Therefore, the validity of the proposed method for voltage event detection can be considered good enough. 


\section{Acknowledgement}

This work is part of the EURAMET joint research project on "Power and Energy" and has received funding from the European Community's Seventh Framework Programme, ERA-NET Plus, under Grant Agreement No. 217257.

\section{References}

[1] CENELEC, "EN 50160: Voltage Characteristics of Electricity Supplied by Public Electricity Networks", 2007.

[2] A.Baggini, "Handbook of Power Quality", John Wiley \& Sons, Ltd, 2008.

[3] A.M.Gaouda, M.Salama, M.R.Sultan, and A.Y.Chikhani, "Power Quality Detection and Classification Using Wavelet-Multiresolution Signal Decomposition", IEEE Transactions on Power Delivery, 14, Oct. 1999.

[4] C.Wong, I.Leong, C.Lei, J.Wu, and Y.Han, "A Novel Algorithm for Phasor Calculation Based on Wavelet Analysis", IEEE Power Engineering Society Summer Meeting, 2001.

[5] D.C.Robertson, O.I.Camps, J.S.Mayer, and W.B.Gish, "Wavelets and Electromagnetic Power System Transients", IEEE Transactions on Power Delivery, 11, 1050, 1058, 1996.

[6] "IEC 61000-4-30 Ed2.0 - Part 4-30: Testing and Measurement Techniques - Power Quality Measurement Methods", 2008.

[7] B.Burke, "The World According to Wavelets", 2nd edition, 1998.

[8] S.Mallat, "A Wavelet Tour of Signal Processing", Academic Press, 2nd edition, 1998.

[9] G.Strang and T.Nguyen, "Wavelet and Filter Banks", Cambridge Press, 87, 113, 1996.

[10] I.Daubechies, "Ten Lectures on Wavelets", SIAM, Philadelphia, 1992. 